\title{
4. Doing Things Collaboratively: Realizing the Advantage or Succumbing to Inertia? ${ }^{1}{ }^{2}$
}

\section{Chris Huxham and Siv Vangen}

The project has worked out, but oh boy, it has caused pain.

- senior health promotion officer, health promotion partnership

Decisions are made by the Alliance Executive, but they keep procrastinating over big decisions ... you can't afford to procrastinate over spending a million pounds.

- information manager, retail property development alliance

Multi-agency work is very slow ... trying to get people moving collectively rather than alone is difficult.

- project officer, young offender community organization

I am under partnership attack from my colleagues.

- operations manager, engineering supply chain

The long catalogue of failed JVs-lcatel/Sharp, Sony/Qualcomm, Lucent/Philips - demonstrates the enormous difficulties in pulling companies like these together.

- a Gartner analyst quoted in the Financial Times, 10 December 2002, p. 8

Not everyone who works daily in collaborative alliances, partnerships or networks reports such negative experiences as those quoted above. Indeed the Financial Times (24 June 2003, p. 14) reports a Nokia executive as saying that their linkages are paying off. Others talk similarly enthusiastically about their partnership experiences:

When it works well you feel inspired ... you can feel the collaborative energy.

However, very many do express frustration. There has been much rhetoric about the value of strategic alliances, industry networks, public service delivery partnerships and many other collaborative forms, but reports of unmitigated success are not common. In this article we explore the nature of the practice of collaboration, focusing in particular on some of the reasons why collaborative initiatives tend to challenge those involved. Two concepts are central to this 
exploration. The first is collaborative advantage. This captures the synergy argument: to gain real advantage from collaboration, something has to be achieved that could not have been achieved by any one of the organizations acting alone. This concept provides a useful 'guiding light' for the purpose of collaboration. The second concept, collaborative inertia, captures what happens very frequently in practice: the output from a collaborative arrangement is negligible, the rate of output is extremely slow, or stories of pain and hard grind are integral to successes achieved.

Clearly there is a dilemma between advantage and inertia. The key question seems to be:

If achievement of collaborative advantage is the goal for those who initiate collaborative arrangements, why is collaborative inertia so often the outcome?

To address this question, and the question of what managers can do about it, we will present a set of seven overlapping perspectives on collaborative management. This is extracted from the theory of collaborative advantage, which has derived from extensive action research over 15 years. We have worked with practitioners of collaboration, in the capacity of facilitators, consultants and trainers, in a wide variety of collaborative situations. We have kept detailed records about the challenges and dilemmas faced by managers, and of comments they make in the course of enacting their collaborative endeavours. Many such statements are reproduced as illustrative examples in this article.

\section{PERSPECTIVE 1: WE MUST HAVE COMIMON AIMS BUT WE CANNOT AGREE ON THEM}

Agreement on aims is an appropriate starting point because it is raised consistently as an issue. Common wisdom suggests that it is necessary to be clear about the aims of joint working if partners are to work together to operationalise policies.

Typically individuals argue for common (or at least compatible), agreed, or clear sets of aims as a starting point in collaboration. Common practice, however, appears to be that the variety of organisational and individual agendas that are present in collaborative situations makes reaching agreement difficult. For example, a board member of an alliance of 120 charities commented on the difficulty of reconciling members' interests. Invariably someone would call to say, 'We don't want you to do that.'

The reasons behind the struggles for agreement may not be obvious. Organisations come together bringing different resources and expertise to the table, which in turn creates the potential for collaborative advantage. Yet organisations also have different reasons for being involved, and their 
representatives seek to achieve different outputs from their involvement. Sometimes these different organisational aims lead to conflicts of interest. Furthermore, for some organisations the joint purpose for the collaboration is perceived as central to achieving organisational purposes, whereas others are less interested and perhaps only involved (reluctantly) as a result of external pressure. Tensions often arise, therefore, because some organisations are very interested in influencing and controlling the joint agenda, and some are reluctant to commit resources to it, and so on. Similarly, individuals too will join the collaboration with different expectations, aspirations and understandings of what is to be achieved jointly. It follows that whilst at first glance it may appear that partners only need be concerned with the joint aims for the collaboration, in reality organisational and individual aims can prevent agreement because they cause confusion, misunderstanding and conflicts of interest. In addition, while some of these various aims may be explicit, many will be taken for granted (assumed) by one partner but not necessarily recognized by another, and many will be deliberately hidden:

My company is really most interested in having access to, and experience of, the Chinese business environment and cares little for the formally declared purpose of the alliance.

On reflection then it is not so surprising that reaching agreement can be very difficult.

Figure 1 - A framework for understanding aims in collaboration

\begin{tabular}{|c|c|c|c|}
\hline $\begin{array}{l}\text { (one participant's } \\
\text { perspective) }\end{array}$ & Explicit & Assumed & Hidden \\
\hline Collaboration Aims & \multicolumn{2}{|c|}{ The purpose of the collaboration } & $\begin{array}{l}\text { By definition, these are } \\
\text { perceptions of joint aims } \\
\text { and so cannot be hidden }\end{array}$ \\
\hline Organisation Aims & \multicolumn{3}{|c|}{ What each organisation hopes to gain for itself via the collaboration } \\
\hline Individual Aims & \multicolumn{3}{|c|}{ What each individual hopes to gain for him/herself via the collaboration } \\
\hline
\end{tabular}

\section{Managing Aims in Practice}

Fig. 1 is a simplified version of a framework of aims in collaborative situations. Its purpose is to facilitate a better understanding of the motivations of those involved, and the ways in which multiple and (sometimes even) conflicting aims can prevent agreement and block progress. In turn, this sort of understanding can help in finding ways of addressing the concerns of all involved.

The framework distinguishes between the various types of aims mentioned above and emphasizes that some aims will be assumed rather than explicitly acknowledged, and many will be deliberately hidden. This framework can be used as an effective tool for gaining insight about the motivations of members of a collaboration - even of one's own! Obviously it is not possible to know others' hidden agendas, but it is possible to speculate on the possibility that they might have some - and even have a guess at what they might be. Trying 
to 'fill in' each of the cells of the framework for each other partner can be enlightening, whether it is done quickly, 'back of an envelope' style, or as a major investigative exercise. Gaining this kind of insight into partners' expectations and aspirations can be very helpful in understanding and judging how best to work with them.

At the general level, the obvious conclusion to be drawn from the framework is that it is rarely going to be easy in practice to satisfy fully the common wisdom. Therein lies the dilemma - clarity of purpose provides much needed direction, yet open discussion can unearth irreconcilable differences! Difficulties that arise out of the need to communicate across different professional and natural languages and different organisational and professional cultures are unlikely to assist the negotiation process. Likewise, concerns about accountability of participants to their own organisations or to other constituents are unlikely to make it easy for individuals to make compromises. Often, the only practical way forward is to get started on some action without fully agreeing the aims. In the words of the manager of an urban regeneration partnership engaged in writing a bid for funding, the task for managers can be to:

find a way of stating the aims so that none of the parties can disagree.

\section{PERSPECTIVE 2: SHARING POWER IS IMPORTANT, BUT PEOPLE BEHAVE AS IF IT'S ALL IN THE PURSE STRINGS}

As with the previous perspective, the 'pain' associated with issues of power is often raised by practitioners of collaboration. Common wisdom is that 'the power is in the purse strings,' which suggests that those who do not have control of the financial resource are automatically deprived of power. Viewed dispassionately, these perceptions quite often seem at odds with 'reality' since most parties do, minimally, have at least the 'power of exit.' A manager in an automotive industry joint venture commented:

The balance of power was seemingly with the U.K. company, who had a majority shareholding, but in reality it was with U.S. company, who knew how closely the investment analysts were watching the joint venture. The threat of pulling out was always in the background.

However, the common practice, unsurprisingly, is that people act as though their perceptions are real and often display defensiveness and aggression.

Looking more closely at where power is actually used to influence the way in which collaborative activities are negotiated and carried out, it is possible to identify different points of power. Many of these occur at a micro level in the collaboration, and would often not be particularly obvious to those involved. One example of a point of power is the naming of the collaboration, since this is likely to influence what it does. Those who are involved in the naming process 
are therefore in a powerful position at that time. Other examples concern invitations to join a collaboration; those who choose who to involve are obviously powerful, but those who choose the process of whom to involve are even more so.

Many points of power relate to communication media and processes. One set of examples concerns the arrangements for meetings. Clearly, any person taking the role of chair or facilitator in a meeting is in a position of power whilst the meeting is in place, but those who get to choose which facilitator to appoint are more subtly and perhaps more significantly powerful. Those who choose the location of a meeting may be in a powerful position, particularly in terms of determining whether it will be on the premises of one of the participants. Those who choose the timing of the meeting are also powerful. It is possible to identify many more points of power that typically are present during collaborative activities.

An important characteristic of points of power is that they are not static. In collaborative situations, power continually shifts. At the macro level, for example, in a pre-startup phase those who get to draw up contracts, write bids for funding or who have direct access to a customer may be powerful. In a start-up phase however, once money is available, those who are given the task of administering the collaboration may be highly powerful in determining many parameters concerned with direction and ways of working. It may only be at later stages that the actual members become active and have the chance to exert power.

Less obvious, but very significant, are the continuous shifts of power at a micro level during all phases. For example, network managers are often in powerful positions between meetings because they are the only people formally employed by the network - and hence the only people who have its agenda as their main concern. They may also have access to the network funds. During meetings, however, members can shift many of the points of power in significant ways, often determining new members, times and locations of meetings as well as influencing agreements about action. Those less centrally involved, such as facilitators or consultants, can be in powerful positions for short periods of time. External influences, such as those from government, can sometimes be extremely powerful in a short-term way as they make demands for reports or responses to initiatives.

\section{Managing Power in Practice}

Issues concerned with control of purse strings are significant, but there are many other points at which power is, in practice, enacted in collaborative settings. All participants have power at one time or another and may frequently have the option to empower themselves. Understanding and exploring the points of power can enable assessment of where and when others are unwittingly or consciously 
exerting power, and where and when others may view them as exerting power. It also allows for consideration of how and when deliberately to exert power. Responding to these insights, however, requires a willingness to accept that manipulative behaviour is appropriate, which some would argue is against the spirit of collaborative working. We will return to this point later.

\section{Figure 2 - The trust-building loop}

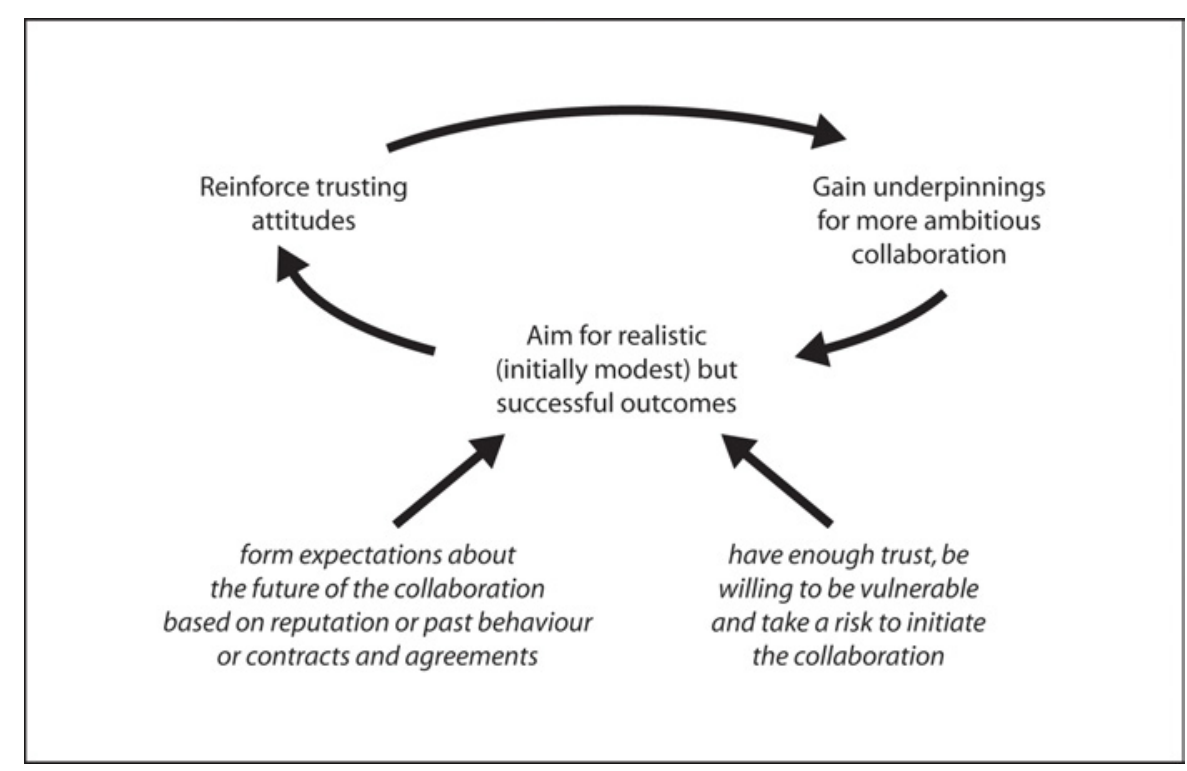

\section{PERSPECTIVE 3: TRUST IS NECESSARY FOR SUCCESSFUL COLLABORATION, BUT WE ARE SUSPICIOUS OF EACH OTHER}

Issues relating to trust are also commonly raised by participants. The common wisdom seems to be that trust is a precondition for successful collaboration. However, while the existence of trusting relationships between partners probably would be an ideal situation, the common practice appears to be that suspicion, rather than trust, is the starting point. Often participants do not have the luxury to choose their partners. Either imposed (e.g. government) policy dictates who the partners must be or, as expressed by the business development manager of the Far East operation of a major oil producer below, the pragmatics of the situation dictate that partners are needed where trust is weak:

You may have to jump into bed with someone you don't like in order to prevent a competitor coming into the market.

This suggests that it is appropriate to pay attention to trust building between partners. 
One way of thinking about trust building is through the loop depicted in Fig. 2. This argues that two factors are important in getting started in a trusting relationship. The first is concerned with the formation of expectations about the future of the collaboration; these will be based either on reputation or past behaviour, or on more formal contracts and agreements. Given the earlier remarks about the difficulty of agreeing on aims in collaborative settings, this in itself is a non-trivial starting point. The second starting point involves risk taking. The argument is that partners need to trust each other enough to allow them to take a risk to initiate the collaboration. If both of these initiators are possible, then the loop argues that trust can gradually be built through starting with some modest but realistic aims that are likely to be successfully realized. This reinforces trusting attitudes between partners and provides a basis for more ambitious collaboration.

\section{Managing Trust in Practice}

The practical conclusion from the trust-building loop is very similar to that concerning the management of aims: sometimes it is better to get started on some small but tangible action and then to allow trust to develop slowly. This incremental approach to trust building would obviously not be relevant if an immediate need to attain a major objective is paramount. In those situations, expectation forming and risk taking would have to be managed simultaneously and alongside other trust-building activities. However, in other situations building trust incrementally is, in principle, appealing. We shall return to it later.

\section{PERSPECTIVE 4: WE ARE PARTNERSHIP-FATIGUED AND TIRED OF BEING PULLED IN ALL DIRECTIONS}

In this perspective it is not so much the common wisdom but the taken for granted assumptions that are to be challenged. One of the most surprising observations about collaborative situations is the frequency with which clarity about who the collaborators are is lacking. Different members often list different partners from each other, and staff who are very centrally involved in managing collaborations often cannot name partners without referring to formal documentation. Reasons for this include the different statuses or commitment that people or organisations have with regard to the network:

They were only involved to provide the financial support ... (rather than as a proper member);

and ambiguity about whether people are involved as individuals or on behalf of their organisations: 
Members were invited to join because of their ethnic background, but the organisations they worked in (which were not specifically concerned with ethnicity issues) then became partners.

The lack of clarity about who partners are is often compounded by the complexity of collaborative arrangements in practice. The sheer scale of networking activities is one aspect of this. Many organisations are involved in multiple alliances. One major electronics manufacturer, for example, is said to be involved in around 400 strategic alliances. Clearly, even with the most coherent alliance management practices, no individual manager is likely to know which partner organisations are involved. Clearly also, multiple alliances must pull the organisation in a variety of different directions. As one senior manager in a division of a multinational computer hardware manufacturer put it:

We have separate alliances with two companies (worldwide operating system providers) that are in direct competition with each other ... there is a lot of conflict within the company over these alliances ... the people involved try to raise the importance of theirs.

The same issue arises in the public sector context, with ever increasing numbers of partnerships and inter-agency initiatives appearing in localities. In this case, however, the problem that is most commonly voiced is 'partnership fatigue,' with individuals often regularly attending meetings of five or six collaborative schemes. More extreme cases occur in this sector too. For example, a manager from a community- based careers guidance organisation commented:

When I heard of the person attending meetings of five partnerships, I thought 'Is that all?!' ... My organisation is involved in 56 partnerships.

There are many other consequences of these multiple initiatives apart from fatigue. One is that some participants try to link agendas across the initiatives, but the links they see relate to the particular combinations of initiatives that they are involved in, which generally do not overlap precisely, if at all, with involvements of other members. Another is that it is hard for any individual to judge when another is inputting the views of their employing organisation or bringing an agenda from another partnership.

In addition to the volume of relationships, there is frequently complexity in the networks of relationships between organisations. For example, the complexity of interacting supply chain networks - in which every supplier has multiple customers, every customer has multiple suppliers, and suppliers have suppliers and customers have customers - is potentially infinite. Many networks of collaborations are, in addition, hierarchical in the sense that collaborations are members of other collaborations. For example, a local government organisation may be a member of a regeneration partnership but also a member of several community collaborations which are in turn members of a community 'umbrella 
group,' which is in turn a member of the regeneration partnership. Similarly, joint ventures may be members of strategic alliances, trade associations may represent their members in policy networks, and so on.

\section{Managing Ambiguity and Complexity in Practice}

Clearly, it is hard for managers to agree on aims, build mutual understanding and manage trust and power relationships with partners if they do not unambiguously know who their partners are. Equally, it is difficult to manage collaborative working in complex systems in which different elements must be affecting each other but there is little clarity on the nature of the inter-relationships.

Diagramming techniques can help in mapping the structure of partnerships. Fig. 3 provides two possible ways of doing this. Obviously this cannot remove the ambiguity and uncertainty completely, but it is generally enlightening at the point of construction and useful as a long-term reminder. As with the aims framework, this exercise can be done in more or less detail.

At a general level, learning how to identify, live with and progress despite ambiguity and complexity is probably the key challenge of this perspective. A careful approach to nurturing relationships must be an essential aspect of this.

\section{PERSPECTIVE 5: EVERYTHING KEEPS CHANGING}

Collaborative structures are commonly talked about as though stability of membership can be taken for granted, at least for a tangible period. The ambiguity and complexity indicated in the previous section would be difficult enough for participants to cope with if that were the case. In practice, however, policy influences, which may be internal but are frequently imposed externally, often generate restructuring of member organisations. Merger and de-merger, new start-ups and closures, acquisitions and sell-offs, and restructurings are all commonplace. In turn, these imply a necessary restructuring of any collaboration in which they participated.

Equally, policy changes in the individual organisations or the collaboration affect the purpose of the collaboration. These may be generated internally - for example, as the result of a revision of strategic direction. Or they may be generated externally - for example, as a result of government policy or major market disturbances. Either way, this in turn implies a shift in the relevance of the collaboration to its members. New members may join and others may leave, and sometimes such changes are imposed:

The problem isn't that their collaboration is not working, but that because of the new policy we are asking them to work differently, which means breaking up established successful and effective working relationships and building new ones. 
Another source of dynamic change comes with individual movements. The manager of a company that was delivering a major service for an alliance partner, for example, commented that the relationship with the partner organisation had been both helped and hindered because:

... the chief executive in the partner organisation was, until recently,

my boss in my own organisation.

The relationships between individual participants in collaborations are often fundamental to getting things done. This makes collaborations highly sensitive to changes in individuals' employment, even if these are simply role changes within one of the participating organisations. Finally, even if all of the above stood still there is often an inherent dynamic. If an initial collaborative purpose is achieved, there will usually be a need to move to new collaborative agendas, and these are likely to imply different membership requirements.

Figure 3 - Example diagramming methods for mapping the complexity of collaborative structures

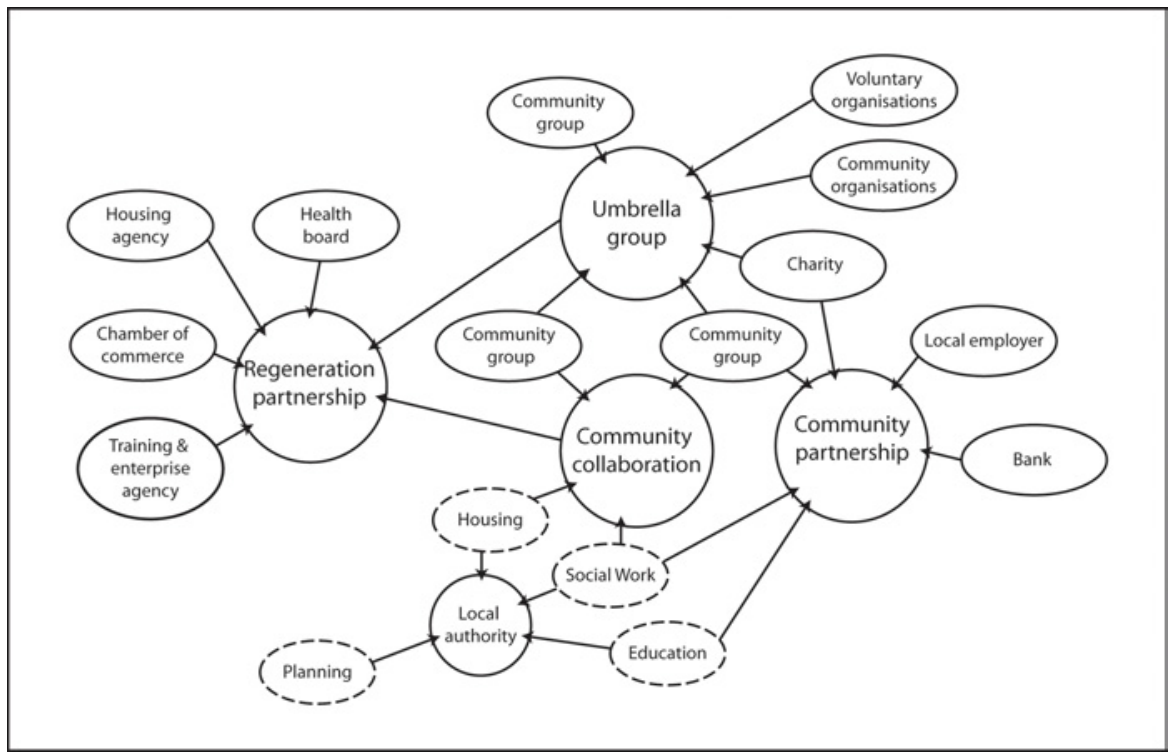

All organisations are dynamic to the extent that they will gradually transform. However, collaborations are sensitive to transformations in each of the partner organisations and therefore may change very quickly. In one example, a collaborative group with an ambiguous structure involving many partners went through three identifiable reincarnations over a three-year period and ended up as a very controlled partnership between two organisations. Its final stated purpose was related to, but definitely not the same as, the original one. It would be reasonable to argue that the final partnership was a different one from the 
original collaborative group, but it is possible to trace a clear lineage from one to the other.

\section{Managing Collaborative Dynamics in Practice}

One obvious conclusion that derives from recognition of the dynamic nature of collaborations is that the appealing trust-building loop (Fig. 2) is inherently extremely fragile. Effort put into building mutual understanding and developing trust can be shattered, for example, by a change in the structure of a key organisation or the job change of a key individual. A practical conclusion, therefore, for those who want to make collaboration work is that the nurturing process must be continuous and permanent. No sooner will gains be made than a disturbance, in the form of a change to one of the partners, will shatter many of them.

\section{PERSPECTIVE 6: LEADERSHIP IS NOT ALWAYS IN THE HANDS OF MEMBERS}

Given the inherent difficulties with collaborative forms that have been discussed so far, the issue of leadership seems highly relevant. Because traditional hierarchies do not exist in collaborative settings, it is appropriate to consider leadership in a general sense, rather than as specifically the realm of senior executives or prominent public figures. Here, we consider leadership as being concerned with the mechanisms that lead to the actual outcomes of a collaboration. Put simply, we are concerned with what 'makes things happen' in a collaboration. More formally, this concern is with the formation and implementation of the collaboration's policy and activity agenda.

Looked at from this perspective, leadership, interestingly, becomes something that is not only enacted by people. Structures and processes are as important in leading agendas as are the participants involved in the collaboration. Thus, for example, a structure in which two organisations only are involved in partnership should allow both organisations good access to the agenda, but clearly excludes others. To take an extreme contrast, a collaboration in which any organisation that wants to be a member may send a representative allows wide access to the agenda in principle, but it can be difficult for any individual to have much influence in practice. Similarly, in the context of collaborative processes, a collaboration for which a major form of communication is through open meetings is going to allow a very different form of access to the agenda from one whose principal mode of communication is through e-mail and/or telephone. Thus, agendas may be led by the type of structure that is in place and the type of processes used. Once again, this challenges a taken for granted presumption about the nature of leadership. Agendas can, of course, also be led by participants, though generally these are emergent, informal leaders rather than those who lead from a position of authority. 
Structures, processes and participants can be thought of as different media through which collaborative leadership is, in practice, enacted. An important point about these media is that all three are largely not controlled by members of the collaboration. Structures and processes are sometimes imposed externally, for example, by government, a corporate headquarters or a funding body. Even if this is not the case, they often emerge out of previous action rather than being explicitly designed by members. Even in the context of 'participants' as the leadership medium, leadership is not solely the role of members of the collaboration. External stakeholders such as customers or local public figures often strongly direct the territory of a partnership or alliance. A strong lead is often also given by support staff who are not strictly members. For example, the information manager of a retail property development alliance commented about his role in moving the alliance members towards agreement about action:

I find that attrition helps ... I am a stubborn old devil.

\section{Managing Leadership Media}

This perspective demonstrates the ease with which collaborations can move out of the control of their membership. Recognizing the at least partial inevitability of this and working around it is part of the practical response required. Diagramming techniques such as those in Fig. 3 may be helpful in exploring the nature of the structure as a first step towards gaining an understanding of its leadership consequences.

For managers who wish to lead more actively, the implication appears to be that part of their activity must be concerned with the design of structures and processes that are effective for the particular purpose, and with monitoring their performance and evolution. We look further at active leadership in the final perspective.

\section{PERSPECTIVE 7: LEADERSHIP ACTIVITIES CONTINUALLY MEET WITH DILEMMAS AND DIFFICULTIES}

Despite the strong contextual leadership derived from structures and processes, participants (whether or not they actually are members) do carry out leadership activities in order to move a collaboration forward in ways that they regard as beneficial. In carrying out these activities, they do affect the outcomes of collaborative initiatives. However they are frequently thwarted by difficulties, so that the outcomes are not as they intend. For example, despite his war of attrition, the information manager quoted above was continuously thwarted in his attempts to create events in which key members of the partnering organisations would jointly consider their modes of thinking and working. Several dates set aside for group workshops were ultimately used for other kinds of meetings, as issues needing immediate attention emerged. 
In practice, much of what is done by those who aim to take a lead in moving a collaboration forward may be said to be fundamentally within the spirit of collaboration. Activities of this sort are highly facilitative and are concerned with embracing, empowering, involving and mobilizing members. However, the same people are also engaged in activities that, on the face of it, are much less collaborative. Many of them are adept at manipulating agendas and playing the politics. We have characterized these kinds of activities as being towards collaborative thuggery after the member of a city partnership who told us that a partnership that he was involved with had been successful:

... because the convenor is a thug ... if people are not pulling their weight

he pushes them out.

He appeared to be arguing that this was a positive and effective mode of leadership.

\section{Managing Leadership Activities}

Does this, then, suggest a dilemma between the ideology of collaborative working and the pragmatism needed to get things done? Not necessarily. One way of thinking about this is to consider the nature of nurturing. Nurturing is often talked about in the context of the gentle care required for fragile plants. However, rather more decisive tactics have to be taken if the object is to nurture an overgrown garden back to health. Chopping down of excess growth and pulling up of weeds are likely to be key activities, in addition to the nurturing back to health of individual plants that have become overpowered by others. Whilst it is not possible to produce hard evidence of this, those who lead more successfully seem to operate from both perspectives - the spirit of collaboration and towards collaborative thuggery - and to continually switch between them, often carrying out both types of leadership in the same act.

\section{REALIZING COLLABORATIVE ADVANTAGE}

Our aim here has been to convey some of the complexity that underlies collaborative situations in a way that should seem real to those involved. Obviously the set of seven perspectives does not, in itself, provide any precise recipes for managerial action. It does, however, provide a dual basis for thoughtful action.

The first basis is through legitimizing the pain and addressing the isolation that people often feel when trapped in collaborative inertia:

I have been working in a health-education partnership ... for about a year, and it is a relief and a reassurance to see that the 'pain and grind' of partnership work exists in other partnerships, not just my situation. 
Like this person, many managers are empowered simply by understanding that the problems they are experiencing are inevitable. This is partly because this awareness increases self-confidence, and partly because it immediately highlights the need to tackle the problem at a different level. Legitimizing a degree of manipulative and political activity through the notion of collaborative thuggery can also be helpful in this respect.

The second, and perhaps more significant, basis for action is through the conceptual handles that the perspectives provide. As presented here in summary, the combined picture gives a sense of the kinds of issues that have to be managed (a more detailed version of each perspective is available). Like the summary, the detailed perspectives do not provide a recipe for good practice, because to do so would be to over-simplify. Rather, they are intended to alert managers to challenges of collaborative situations that will need active attention and nurturing if problems of collaborative inertia are to be minimized. Each perspective provides a particular view on this, and can be used in isolation to stimulate thinking about that in particular. However, the issues raised by each perspective overlap with those raised by others, so the combination of perspectives always needs to be in the background, even if the focus at a particular time is a specific one. Many of the challenges are inherent, and there are often tensions between directly opposed possible ways of tackling them. This approach to practical support regards the action to be taken as a matter for managerial judgement. This includes making informed judgements about the resource that needs to be available to support the nurturing activities.

\section{DON'T WORK COLLABORATIVELY UNLESS YOU HAVE TO}

One definite conclusion can, however, be drawn. That is, that making collaboration work effectively is highly resource-consuming and often painful. The strongest piece of advice to managers (and policy makers) that derives from the above perspectives, therefore, is 'don't do it unless you have to.' Put rather more formally, the argument is that unless potential for real collaborative advantage is clear, it is generally best, if there is a choice, to avoid collaboration. It is worth noting, however, that collaborative advantage sometimes comes in non-obvious forms and may be concerned with the process of collaborating - for example from the development of a relationship with a partner - rather than the actual output.

\section{SELECTED BIBLIOGRAPHY}

This article draws on the theory of collaborative advantage, which we have developed gradually from extensive research with practitioners of collaboration over the last 15 years. The notions of Collaborative Advantage and Collaborative Inertia are central to this theory. Collaborative Advantage was first used in this 
way in the early 1990s. See for example, C. Huxham and D. Macdonald, 'Introducing Collaborative Advantage,' Management Decision, 1992, 30(3), 50-56. Rosabeth Moss Kanter used the term differently in her 1994 article 'Collaborative Advantage: The Art of Alliances,' Harvard Business Review, 72(4), 96-108. Collaborative inertia was introduced in C. Huxham, 'Advantage or Inertia: Making Collaboration Work,' in R. Paton, G. Clark, G. Jones, and P. Quintas (Eds.), The New Management Reader (London: Routledge, 1996, 238-254). Theory relating to the aims framework of perspective one can be found in C. Eden and C. Huxham, 'The Negotiation of Purpose in Multi-Organisational Collaborative Groups,' Journal of Management Studies, 2001, 38(3), 351-369. A detailed discussion on the points of power in perspective two can be found in C. Huxham and N. Beech, 'Points of Power in Interorganisational Forms: Learning from a Learning Network,' Best 10\%, Proceedings of the Academy of Management Conference, 2002. The development of the trust-building loop and its implication for the management of trust in perspective three is explored in S. Vangen and C. Huxham, 'Nurturing Collaborative Relations: Building Trust in Inter-organisational Collaboration,' Journal of Applied Behavioral Science, 2003, 39(1), 5-31. A detailed exposition of perspectives four and five can be found in C. Huxham and S. Vangen, 'Ambiguity, Complexity and Dynamics in the Membership of Collaboration,' Human Relations, 2000, 53(6), 771-806. For a detailed discussion on the conceptualization and enactment of leadership in perspectives six and seven see C. Huxham and S. Vangen, 'Leadership in the Shaping and Implementation of Collaboration Agendas: How Things Happen in a (Not Quite) Joined Up World,' Academy of Management Journal (Special Forum on Managing in the New Millennium), 2000, 43(6), 1159-1175; and S. Vangen and C. Huxham, 'Enacting Leadership for Collaborative Advantage: Dilemmas of Ideology and Pragmatism in the Activities of Partnership Managers,' British Journal of Management, 2003, 14, 61-74.

Chris Huxham is a Fellow of the (UK) Advanced Institute of Management Research and a professor of management in the University of Strathclyde, Graduate School of Business. (chris@gsb.strath.ac.uk)

Siv Vangen is a senior lecturer in management at The Open University Business School.

They have developed the Theory of Collaborative Advantage through an action research programme spanning 15 years. During this period they have worked with a large number of individuals and organisations involved in partnerships, alliances, networks and joint ventures across all sectors.

\section{ENDNOTES}

1 This paper was originally published in Organizational Dynamics, Vol. 33, No. 2, pp. 190-201, 2004. It is reprinted here by permission of the publisher. 


\section{Collaborative Governance}

2 Acknowledgments: Colin Eden and Nic Beech have been involved in developing specific elements of this theory. Their perspectives and styles of researching have provided invaluable insights. We would also like to thank Murray Stewart and Robin Hambleton for the research collaboration that led to our work on collaborative leadership. Many, many practitioners have been wittingly and unwittingly involved in the development of this theory; they are too numerous to name, but our thanks are due to them all. We would like to acknowledge the support for this research of the U.K. Economic and Social Research Council (ESRC) and Engineering and Physical Sciences Research Council (EPSRC) under ESRC grant numbers 000234450 and L130251031 and the ESRC/EPSRC Advanced Institute of Management Research grant number RES-331-25-0016. 